\title{
城市生活垃圾分类处理模式探究
}

汪小会 关文义

安徽国祯环卫科技有限公司

DOI:10.32629/eep.v2i10.500

[摘 要] 城市生活垃圾的分类制度能够有效解决生活垃圾混收、资源浪费、污染环境的现状。本文针对城市生活垃圾特性及不同来源探究城 市生活垃圾分类处理模式,并对目前城市生活垃圾分类存在的问题进行详细分析,提出相应的改进对策。

[关键词] 城市生活垃圾; 分类制度; 生活垃圾特性; 来源; 模式

我国城市生活垃圾分类推广工作已历时多年。北京在上世纪 90 年代中 期, 就开始提出垃圾分类概念。2000年, 住建部公布了 8 个重点城市作为生 活垃圾分类试点城市。住建部于 2019 年提出了新的要求, 所有地级及以上 的城市将全面开展垃圾分类工作。这些表明, 实现城市生活垃圾分类制度 至关重要。本文作者将根据城市生活垃圾不同来源及生活垃圾组成来探究 城市生活垃圾分类处理模式。

\section{1 城市生活垃圾特性}

城市生活垃圾按照相应的特性可分为可回收物、厨余垃圾、有害垃圾、 其他垃圾 ${ }^{[1]}$ 。生活垃圾的物理组成成分受社会经济、生活习惯、文化习俗、 自然条件等因素影响。城市生活垃圾组成成分如图1所示。图1表明, 城市 生活垃圾中可回收物约占 $20 \%$ 左右, 厨余垃圾约占 $45 \%$ 。说明, 城市生活垃圾 中资源化利用的物质逐渐升高, 而有机质含量高的厨余垃圾占比也在逐渐 增大。

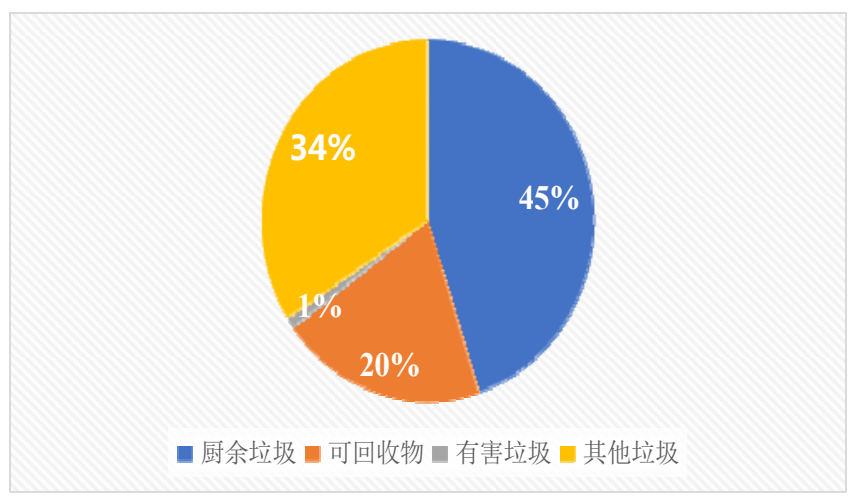

\section{2 城市生活垃圾来源}

图1 城市生活垃圾组成成分

城市生活垃圾产生场所主要包括居住区、公共机构、农贸市场、公共 场所。居住区主要指城市居民居住的小区、公寓。公共机构主要指党政机 关、团体、学校、企事业单位以及办公等场所。公共场所主要指机场、火 车站、长途客运站、公交场站、文化体育场所、公园广场、商业设施等公 共场所。

\section{3 不同来源的分类模式}

居住区实行四分法, 即可回收物、有害垃圾、暦余垃圾、其他垃圾。 公共机构所实行四分法; 农贸市场应实行二分法, 政余垃圾、其他垃圾。 公共场所实行三分法, 可回收物、有害垃圾、其他垃圾。公共场所内设有 食堂或餐饮企业应增加厨余垃圾分类, 实行四分法。

\section{4 “四分法”生活垃圾收运处理体系的建立}

城市居民将日常产生的生活垃圾成四类, 分类投放, 保洁员分类收集。 为了便于住宅区垃圾分类管理以及分类收运, 住宅区要实行定时定点投放
生活垃圾。

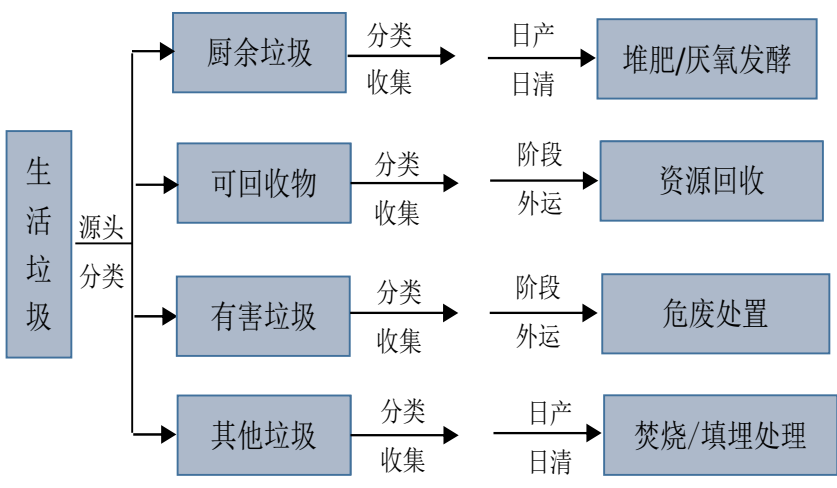

图2 “四分法”活垃圾分类收集处理流程示意图

对产生量较大的厨余垃圾进行分类收集, 日产日清, 运输至末端处理 厂进行堆肥或戻氧发酵处理。其他垃圾运输至末端处理厂进行填埋或焚烧 处理。可回收物可设置暂存处, 阶段性外运至资源回收公司进行资源化处 理。有害垃圾产生量较小, 可一个季度甚至半年运输一次, 交由有相关资质 的危废处置公司处置。

\section{5 城市生活垃圾分类存在的问题}

针对目前我国城市垃圾分类存在的弊端进行分析, 总结如下。

5.1 垃圾分类参与率低、准确率低

居民参与率、分类准确率是垃圾分类的重要评价指标。调查报告 ${ }^{[2]}$ 表明, 居民对垃圾分类管理都持积极肯定的态度, 但是分类的参与度和准 确性都比较低, 垃圾分类设施、宣传板沦为摆设。我国居民法分类知晓率 很高, 但真正参与分类的很少, 能够准确分类的更少。城市生活垃圾分类制 度的持续实施的制约因素主要是参与率低、准确率低。

5.2 污染者付费制度的不完善

据不完全统计, 目前我国有 300 多个城市在一定程度上实行了城市生 活垃圾处理收费制度, 但对垃圾分类收费制度还未完全实行。2018年11月 山西省发布了《关于完善固体废物处理收费机制的通知》, 首次提出分类 垃圾实行计量收费, 收费标准按照低于混合垃圾收费标准的原则制定。 2019年7月1日 《上海市生活垃圾管理条例》正式实施, 规定个人混合投放 垃圾最高可罚 200 元, 单位混装混运, 最高则可罚 5 万元。目前实施收费制度 的省份较少, 垃圾收费制度还不完善, 征收主体不明确。

5.3 分类投放设施不配套

研究表明 ${ }^{[3]}$, 是否设置分类垃圾箱、分类垃圾桶以及分类收集亭有利 于城市居民进行生活垃圾源头分类。分类投放设施不配套将导致居民无法 进行生活垃圾的源头分类。

5.4 分类收运处理设施不配套 


\section{环境保护中的污染源自动监控系统应用}

何美青

内蒙古汇众环保科技有限公司包头分公司

DOI:10.32629/eep.v2i10.472

[摘 要] 目前,我国对于环境保护十分重视,环境保护是经济发展过程中需要考虑的重要因素之一,污染源自动监控系统的建立与运用对环境保 护发挥着重要的作用,能够有效监控污染源, 本文分析了环境保护工作中污染源自动监控系统的应用方式,提出建立重点污染源自动监控体系,建 立科学的减排指标, 充分利用自动监控数据等。

[关键词] 环境保护; 污染源; 自动监控系统; 应用方式

\section{引言}

近几年, 环境问题日益突出, 严重影响到了人们的生活, 环保问题受 到了越来越多人的重视, 我国加大了环保的投入力度, 从国外引进先进 的污染源自动监测系统, 来改善我国环保监测技术。该技术的应用为环 保工作提供了大量准确可靠的污染源自动监测数据。这些数据可以为环 保工作方向、环境监督管理、环境影响评价提供依据, 提高环保工作的 质量和效率。

\section{1 监控污染源对于环境保护的重要性}

众所周知, 对于环境污染问题而言, 污染源是产生污染问题的重要源 头, 因此, 想要有效治理环境污染问题, 光是依靠污染产生之后的治理工作 完全不够。结合当前我国环境问题来看, 人类自身活动是引起环境污染的 主要源头, 例如, 人们日常生活中所产的垃圾以及废水等, 或者企业在进行 生产活动过程中, 释放相关有害物质, 这些都与人们的日常行为息息相关, 并且最终会直接反作用于人们的身上。近些年来, 人们的疾病种类呈现多 样化趋势发展, 有关癌症的患者数量也在逐渐增加, 人类想要保持健康长 久的发展, 需要创造一个良好的生态环境, 因此, 必须从环境问题中的污染 源着手, 对污染源进行严格控制, 只有这样才能够使环境污染物排放减少, 使我国环境生态问题恢复平衡。

\section{2 环境保护工作中污染源自动监控系统的应用}

2.1 建立客观公平的总量控制及排污税收费标准

总量控制和排污税收费是环境治理中的重要监管方式之一, 对污染治 理具有良好的推动作用。在环境监控体系的建立过程中要求积极为环境治

垃圾分类是个系统工程, 分类投放、分类收集、分类运输四个环节缺一不 可 ${ }^{[4]}$ 。目前, 大部分城市还没有建设配套的垃圾分类收运系统, 没有配套的 分类收集车、转运车, 导致了大部分生活垃圾还是采用混收的方式。大部 分城市也没有配套的处置设施, 垃圾分类后端处置没有跟上前期分类的节 奏。后端处置, 是全世界垃圾处理的最大瓶颈所在, 后端分类处置不彻底, 导致整个生活垃圾分类处理链条的断层。

\section{6 建议}

针对以上城市生活垃圾分类重难点分析, 提出以下建议。

(1) 持续加强对城市生活垃圾分类的宣传引导, 在有条件的小区或公 共场所组织督导员指导居民分类投放生活垃圾。公共机构可以建立垃圾分 类考核机制, 将垃圾分类考核机制纳入工作绩效考核机制, 对于不参与垃 圾分类及垃圾分类不正确的扣除绩效工资。通过监督和考核的方式让居民 逐渐养成垃圾分类良好习惯。

（2）政府及相关部门应 “分步骤、分层次、有目标” 完善城市生活垃 圾分类处置收费制度, 明确收费对象, 完善收费体系。
理提供充分的标准, 以此为环境治理工作提供指导。环境监控体系的建立 能够有效促进这一治理标准的制定, 为环境治理标准的制定提供了充分的 数据理论支撑, 从而有效优化环境治理工作。治理标准的制定是一项较为 综合性与复杂化的工作体系, 需要充分综合地考量多种污染源的排放方 式、排放量, 从而估算其可能会给环境造成的不良, 这需要一套测算科学体 系的建立与支撑, 环境监控体系在这一环节显示出了重要的意义与价值。烟 气中排放的二氧化硫排放量和废水中化学需氧量排放量是目前排污总量 和收费衡量的重要因子, 也是环境污染治理过程中的重点内容之一。自动 监控数据体系的建立与运用能够及时监测排污量, 从而在此基础上制定出 对相关企业的排污收费依据。物料衡算方法与监督性监测数据的运用能够 充分检测企业超标排污时段的污染物排放量, 充分掌握企业的排放口的排 污情况。通过制定排污收费标准从经济杜杆的作用上达到污染治理的效 果。通过自动监控系统, 对排放废气与废水企业建立总量控制体系, 结合其 总量对其建立排污收费标準, 通过排污收费指标的控制减少废水和废气企 业对环境的污染, 达到环保效果。

2.2加强污染源自动监控等环保管理制度, 提高企业管理效率

想要促使污染源自动监控工作有序开展, 首先要对污染源自动监控管 理制度进行完善, 只有这样才能为自动监控工作提高保障。在此过程中, 相 关企业要对自身管理人员进行定期培训, 提高管理人员的专业素质, 除此 之外, 还要严格规范系统操作流程, 对于异常超标情况, 要及时分析原因, 并且提出行之有效的政策, 确保污染源自动监控系统得以正常运行。环保 部门要针对污染源自动监控系统加强自身的监管力度, 最终使该系统得以

(3) 科学合理配置垃圾分类投放设施，引导居民垃圾分类意识。在小区 要按照相应户数配置相应数量的分类投放设施, 分类投放点的位置要合理, 便于居民投放垃圾。公共结构、公共场所以及农贸市场应根据垃圾日产生 量合理配置分类垃圾收集设施。

(4) 城市需要建立较完整的垃圾分类收运处理体系, 明确分类垃圾运 输方式和最终处理方式。

[参考文献]

[1]姚建明,城市生活垃圾分类处理及对策分析 [J].建筑工程技术与设 计,2018,(36):17.

[2]蒋点珈,城市生活垃圾源头分类收集的调查分析[J].资源节约与环 保,2018,(12):105-106.

[3]谭梦,城市生活垃圾源头分类的影响因素研究 [J]. 建筑与生 活,2019,(3):23

[4]孙乐岩,中国城市生活垃圾分类现状分析及改进对策,2019,(1):64-67. 